\title{
Rate of Iron Carburization by Carbon in Slags through Carbon/Slag and Slag/Metal Reactions at $1723 \mathrm{~K}$
}

\author{
Hideki ONO, ${ }^{1)}$ Kenji TANIZAWA ${ }^{21}$ and Tateo USUI ${ }^{31}$ \\ 1) Division of Materials and Manufacturing Science, Graduate School of Engineering, Osaka University, 2-1 Yamadaoka, Suita, \\ Osaka, 565-0871 Japan. $\quad$ 2) Graduate Student, Graduate School of Engineering, Osaka University, 2-1 Yamadaoka, Suita, \\ Osaka, 565-0871 Japan. $\quad 3$ 3) Formerly Division of Materials and Manufacturing Science, Graduate School of Engineering, \\ Osaka University, 2-1 Yamadaoka, Suita, Osaka, 565-0871, Japan. Now at Fukui University of Technology.
}

(Received on January 24, 2011; accepted on March 2, 2011)

\begin{abstract}
The carbide capacity of $\mathrm{CaO}-\mathrm{SiO}_{2}-\mathrm{Al}_{2} \mathrm{O}_{3}$ slags and the rate of iron carburization through successive phases of carbon, slag, and metal are measured at $1723 \mathrm{~K}$. The carbide capacity of high-basicity slag is higher than that of simulated blast-furnace (BF) slag. The iron carburization rate through $\mathrm{CaO}-\mathrm{SiO}_{2}-\mathrm{Al}_{2} \mathrm{O}_{3}$ slags is much smaller than the rate of direct carburization or that through slags including iron oxide. It is found that the rate of carburization of iron through slags increases with increasing slag basicity. The apparent rate constant of the carburization reaction is derived to be $k=2.71 \times 10^{-5} \mathrm{~mol} /\left(\mathrm{m}^{2} \mathrm{~s}\right)$ for the simulated BF slag and $k=8.00 \times 10^{-5} \mathrm{~mol} /\left(\mathrm{m}^{2} \mathrm{~s}\right)$ for the high-basicity slag. The rate increases with increasing slag basicity, increasing carbide capacity, and decreasing oxygen partial pressure.
\end{abstract}

KEY WORDS: carburization; carbon; iron; slag; iron making.

\section{Introduction}

The energy consumption of the iron and steel industries is almost $12 \%{ }^{1)}$ of domestic consumption in Japan. $\mathrm{CO}_{2}$ discharge in the iron and steel industries accounts for $16 \%{ }^{2)}$ of the gross domestic discharge in Japan. Recently, to reduce energy and carbon consumption, pellets or iron ore sinter containing carbon have been used as a blast-furnace (BF) feed. It has been reported that when iron ore comes into contact with carbon on the microscale, reduction and Boudoir reactions proceed at the same site; the reduction equilibrium temperature decreases because the coupling reaction lowers the activation temperature of the reducing reaction. ${ }^{3)}$ By applying this reaction profile, a direct reduction process using iron ore sinter containing carbon, in which the iron ore and carbon are in close contact, has already been developed. ${ }^{4)}$ When pellets or iron ore sinter containing carbon are used as a BF feed, the reduction equilibrium temperature is lowered, and the $\mathrm{CO}$ gas utilization ratio is improved. A significant reduction in material ratios can therefore be expected. However, many problems have also been reported in the use of pellets or iron ore sinter containing carbon as a $\mathrm{BF}$ feed; these include heating and reduction delays in the upper part of the BF shaft, ${ }^{5,6}$ and the lowering of the strength $^{7)}$ arising from the influence of combined or adhesion water.

When pellets or iron ore sinter containing carbon are heated and reduced under BF conditions, the reduction reaction starts at a lower temperature and proceeds faster than in the case of normal pellets or iron ore sinter. After reduction of iron oxide by the included carbon, the reaction is considered to proceed in the following order: melting of the slag components, carburization of the reduced iron, and melting of the carburized iron. At this point, a problem arises, i.e., the difficulty of separating the slag components from the reduced iron. ${ }^{8)}$ The cause is thought to be as follows. Iron ore particles are generally composed of iron oxide and gangue minerals. When pellets or iron ore sinter including carbon are heated and reduced under BF conditions, first, the included carbon initiates reduction of iron oxide and reduced iron is formed. When the sample is heated further, softening and melting of the gangue minerals begin, and then the reduced iron melts. After melting, the metal coheres, and the slag components are extruded and surround the metal as a result of differences in surface tension (slag: $0.2-0.4 \mathrm{~N} / \mathrm{m}$, metal: $1.6-1.8 \mathrm{~N} / \mathrm{m}$ ). ${ }^{9)}$ The process results in the metal being surrounded by slag.

One method which has been considered for solving this problem is enhancement of the carburization of the metal particles. Carburization enhances aggregation coarsening of the metal, which promotes the separation of the slag and the metal; ${ }^{10,11)}$ i.e., enhancing the carburization and melting of the reduced iron is expected to cause separation of the slag and the metal. So, in this work, as a fundamental of slag design, we investigate the transport phenomena of carbon to metal through slags, with the aim of achieving lower-temperature and faster carburization reactions. The carburization rate of iron by carbon in slags through carbon/slag and slag/metal reactions is measured at $1723 \mathrm{~K}$.

\section{Experimental}

\subsection{Slag Sample Preparation}

Two kinds of slag are used in this work. One is a simu- 
lated BF slag and the other is a high-basicity slag. The slag compositions are shown in Table 1. These slags have low melting points in the $\mathrm{CaO}-\mathrm{SiO}_{2}-\mathrm{Al}_{2} \mathrm{O}_{3}$ system, as seen in Fig. 1.

$\mathrm{CaO}$ made from reagent grade $\mathrm{CaCO}_{3}$, and reagent grade $\mathrm{SiO}_{2}$ and $\mathrm{Al}_{2} \mathrm{O}_{3}$ were mixed in fixed proportions and placed in a carbon crucible $(36 \mathrm{~mm} \times 42 \mathrm{~mm} \times 80 \mathrm{~mm})$. The sample was inserted into an electrical resistance furnace and the temperature was held at $1723 \mathrm{~K}$ in an $\mathrm{Ar}-\mathrm{CO}$ mixture at flow rates of Ar: $200 \mathrm{~cm}^{3} / \min (\mathrm{STP})$ and CO: $20 \mathrm{~cm}^{3} / \mathrm{min}$ (STP) for $20 \mathrm{~h}$. The sample was then withdrawn from the furnace and cooled rapidly in an Ar atmosphere. The slag surface was shaved off, crushed, and used as the slag sample.

\subsection{Analysis of Carbon Content of Slags}

In one series of experiments, $7.5 \mathrm{~g}$ of the prepared slag were placed in an $\mathrm{MgO}$ crucible $(23 \mathrm{~mm} \times 30 \mathrm{~mm} \times 50 \mathrm{~mm})$ (condition i). In another series of experiments, a pure iron sheet (14 $\mathrm{mm} \times 14 \mathrm{~mm} \times 0.5 \mathrm{~mm}$, purity 99.5 mass\%) was placed in an $\mathrm{MgO}$ crucible with $7.5 \mathrm{~g}$ of the prepared slag (condition ii). The difference between experimental conditions (i) and (ii) is the presence of the iron sheet, i.e., under condition (i), only dissolution of the carbon in the slag takes place. In contrast, under condition (ii), it is necessary to take carbon transport among three phases (carbon, slag, and metal) into account. The $\mathrm{MgO}$ crucible was placed in a carbon crucible $(36 \mathrm{~mm} \times 42 \mathrm{~mm} \times 80 \mathrm{~mm})$, and inserted in the furnace. The sample was heated from room temperature in an Ar atmosphere. When the temperature reached $1723 \mathrm{~K}$, the sample was kept at this temperature for $15 \mathrm{~min}$, and $0.25 \mathrm{~g}$ of carbon powder were placed on the molten slag. The sample was then equilibrated in an Ar-CO mixture [Ar: $200 \mathrm{~cm}^{3} / \mathrm{min}$ (STP), CO: $2 \mathrm{~cm}^{3} / \mathrm{min}$ (STP)]. The equilibration time was predetermined to be $20 \mathrm{~h}$ by investigating the time dependence of the carbon content of the slag and

Table 1. Chemical compositions of slags.

\begin{tabular}{c|c|c|c}
\multicolumn{1}{|c}{} & \multicolumn{2}{c}{ (mass\%) } \\
\hline Simulated B.F. slag & 40 & 40 & 20 \\
\hline High basicity slag & 50 & 6.6 & 43.4 \\
\hline
\end{tabular}

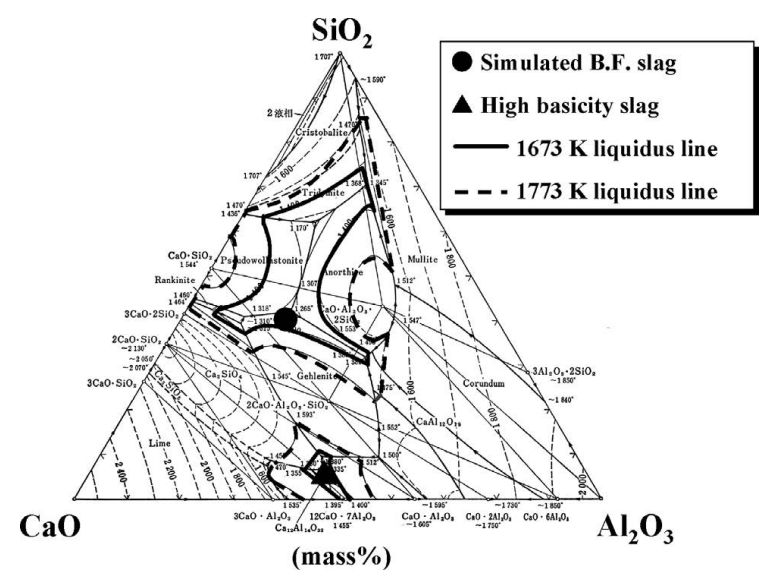

Fig. 1 Compositions of slags plotted on a $\mathrm{CaO}-\mathrm{SiO}_{2}-\mathrm{Al}_{2} \mathrm{O}_{3}$ phasediagram. the initial carbon content. The sample was withdrawn from the furnace, and the carbon content of the slag was analyzed by a combustion/electrical conductivity method.

\subsection{Measurement of Iron Carburization Rate through Slags}

An iron sheet $(14 \mathrm{~mm} \times 14 \mathrm{~mm} \times 0.5 \mathrm{~mm}$, purity 99.5 mass\%) was placed in an $\mathrm{MgO}$ crucible. Prepared slag (7.5 g) was placed on the iron sheet. The $\mathrm{MgO}$ crucible was placed in a carbon crucible and inserted into the furnace. The sample was heated up to $1723 \mathrm{~K}$ from room temperature and held at that temperature for $15 \mathrm{~min}$ in an Ar atmosphere. After the slag sample had melted, $0.25 \mathrm{~g}$ of carbon powder were placed on the molten slag. In preliminary experiments, the slag mixed with carbon was used, and the influence of the entrainment of carbon in the slag was investigated. The results suggested that the influence of carbon entrainment in the slag can be ignored. The sample was then kept for 1 to $25 \mathrm{~h}$ in an Ar-CO mixture at flow rates of Ar: $200 \mathrm{~cm}^{3} / \mathrm{min}$ (STP) and CO: $2 \mathrm{~cm}^{3} / \mathrm{min}$ (STP). The sample was withdrawn from the furnace. After the experiments, the carbon content of the iron was analyzed by high-frequency combustion/infrared absorption.

\section{Results}

\subsection{Carbon Solubility in Slags}

The carbon contents of the slags are shown in Table 2. In the simulated BF slag, there was no difference between the carbon content under condition (i) and that under condition (ii). In contrast, for the high-basicity slag, it was found that the carbon content of the slag under condition (ii) was lower than that that under condition (i).

Table 2. Carbon contents of slags at $1723 \mathrm{~K}$.

\begin{tabular}{l|c|c|c|c}
\multicolumn{2}{|c}{} & \multicolumn{2}{c}{ (mass\%) } \\
\hline \multirow{2}{*}{ Simulated B.F. slag } & \multicolumn{2}{|c|}{ (i) } & \multicolumn{2}{c}{ (ii) } \\
\cline { 2 - 2 } & 0.004 & \multirow{2}{*}{0.0035} & 0.003 & \multirow{2}{*}{0.004} \\
High basicity slag & 0.003 & & 0.005 & \\
\cline { 2 - 2 } & 0.008 & \multirow{2}{*}{0.0075} & 0.004 & \multirow{2}{*}{0.0045} \\
& & 0.005 & \\
\hline
\end{tabular}

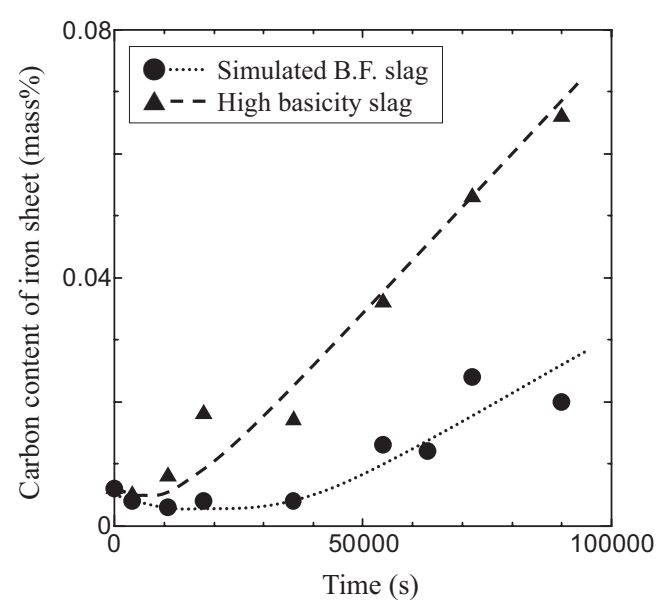

Fig. 2. Variations in carbon content of iron sheet with time at $1723 \mathrm{~K}$ 


\subsection{Iron Carburization through Slags}

The variations in the carbon content of the iron sheet with time are shown in Fig. 2. It was found that the carbon content increased with time in both slags. The carburization rate with the high-basicity slag was higher than that with the simulated BF slag. In both cases, for a period after the start of the experiments, the carbon content of the iron did not increase, and the carbon content was almost constant or became lower than the initial value. This period was longer for the simulated BF slag than for the high-basicity slag. In both experiments, the iron carburization rate through the slag was slow, and the carbon content was much lower than 1.04 mass\%, which is the liquidus composition of the $\mathrm{Fe}-\mathrm{C}$ system at $1723 \mathrm{~K}$.

\section{Discussion}

\subsection{Dissolved Form and Solubility of Carbon in Slags}

4.1.1. Dissolved Form of Carbon in Slags

Carbon dissolved in slag is considered to be in the form of a carbonate ion $\left(\mathrm{CO}_{3}^{2-}\right)$ or a carbide ion $\left(\mathrm{C}_{2}^{2-}\right)$, according to Eqs. (1) and (2), respectively. ${ }^{12,13)}$

$$
\begin{array}{r}
\mathrm{CO}_{2}(\mathrm{~g})+\mathrm{O}^{2-} \text { (in slag) }=\mathrm{CO}_{3}^{2-} \text { (in slag) } \\
2 \mathrm{C}(\mathrm{s})+\mathrm{O}^{2-}(\text { in slag })=\mathrm{C}_{2}^{2-}(\text { in slag })+1 / 2 \mathrm{O}_{2}(\mathrm{~g})
\end{array}
$$

The carbon-absorption ability of a slag is estimated from the carbonate capacity, $C_{\mathrm{CO}_{3}^{2-}}$, and the carbide capacity, $C_{\mathrm{C}_{2}^{2-}}$, expressed by Eqs. (3) and (4), respectively:

$$
\begin{gathered}
C_{\mathrm{CO}_{3}^{2-}}=\frac{\left(\operatorname{mass} \% \mathrm{CO}_{3}^{2-}\right)}{P_{\mathrm{CO}_{2}}} \\
C_{\mathrm{C}_{2}^{2-}}=\frac{\left(\operatorname{mass} \% \mathrm{C}_{2}^{2-}\right) \cdot P_{\mathrm{O}_{2}}^{\frac{1}{2}}}{a_{\mathrm{C}}^{2}}
\end{gathered}
$$

where $a_{\mathrm{C}}$ denotes the activity of carbon relative to the pure solid, $P_{\mathrm{O}_{2}}$ the oxygen partial pressure, and (mass $\% i$ ) the $i$ content of slag (mass $\%)$. The carbonate and carbide capacities are functions of temperature and the slag composition. Eqs. (3) and (4) show that the amount of carbide ions increases when the oxygen partial pressure is lower, and the amount of carbonate ions increases when the $\mathrm{CO}_{2}$ partial pressure is higher. Under the present reducing conditions (the $\mathrm{CO}_{2}$ partial pressure is very low), the carbide ion is considered to be the dominant form of carbon in the slag. Eq. (2) shows that the carbide capacity increases when the basicity of the slag is higher, which shows that carbon dissolves easily in the slag. The values for the carbide capacities in the $\mathrm{CaO}-\mathrm{SiO}_{2}-\mathrm{Al}_{2} \mathrm{O}_{3}$ system have been measured previously and are shown in Fig. 3. ${ }^{14}$ )

\subsubsection{Carbon Solubility in Slags}

As shown in Table 2, the carbon content of the highbasicity slag under condition (ii) is lower than that under condition (i). This is thought to be because condition (ii) relates to the three phases (carbon, slag, and metal), and does not attain total equilibrium among the three phases. Accordingly, the carbon content of the slag under condition (ii) is lower than that under condition (i), in which the equilibrium between two phases (carbon and slag) is investigat-

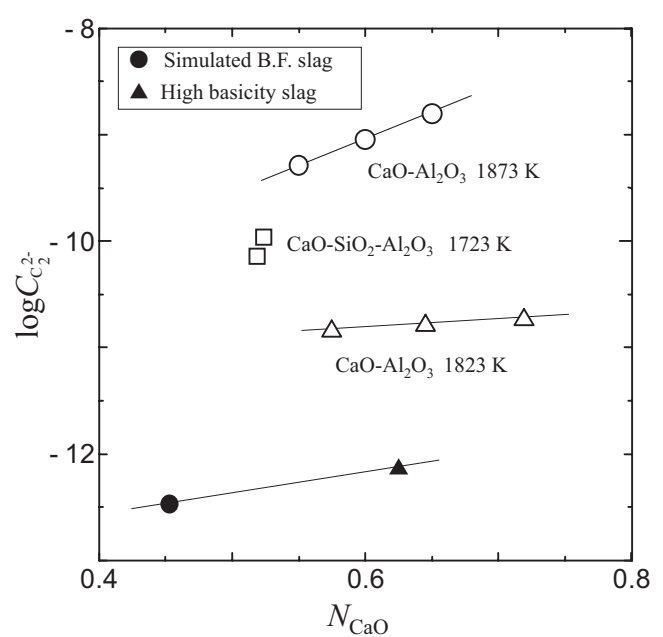

Fig. 3. Carbide capacities of $\mathrm{CaO}-\mathrm{Al}_{2} \mathrm{O}_{3}\left(-\mathrm{SiO}_{2}\right)$ system.

ed. The results under condition (i), which can be considered to attain equilibrium, are therefore, used as the equilibrium carbon contents of the slag in determining the carbidecapacity values expressed by Eq. (4). Under the experimental conditions in this work $\left[1723 \mathrm{~K}, \mathrm{Ar}: 200 \mathrm{~cm}^{3} / \mathrm{min}\right.$ (STP), $\mathrm{CO}: 2 \mathrm{~cm}^{3} / \mathrm{min}$ (STP)], the partial pressures of oxygen and $\mathrm{CO}_{2}$ can be calculated from the equilibria of the following reactions. $^{15)}$

$$
\begin{gathered}
\mathrm{CO}_{2}(\mathrm{~g})+\mathrm{C}(\mathrm{s})=2 \mathrm{CO}(\mathrm{g}) \\
\Delta G^{0} / \mathrm{J}=172000-175 T \\
2 \mathrm{C}(\mathrm{s})+\mathrm{O}_{2}(\mathrm{~g})=2 \mathrm{CO}(\mathrm{g}) \\
\Delta G^{0} / \mathrm{J}=-222000-178 T
\end{gathered}
$$

When the CO partial pressure $\left(P_{\mathrm{CO}}\right)$ is $0.0099 \mathrm{~atm}$, and the carbon activity $\left(a_{\mathrm{C}}\right)$ is 1 , the partial pressures of oxygen and $\mathrm{CO}_{2}$ are calculated to be $P_{\mathrm{O}_{2}}=9.28 \times 10^{-21}$ atm and $P_{\mathrm{CO}_{2}}=$ $1.13 \times 10^{-8} \mathrm{~atm}$, respectively, from Eqs. (5) and (6). From Eq. (4), the carbide capacity is determined to be $3.37 \times 10^{-13}$ for the simulated BF slag and $7.23 \times 10^{-13}$ for the high-basicity slag; these values are also shown in Fig. 3. From Fig. 3, it is found that the carbide capacities derived in this work are smaller than the values reported previously for the $\mathrm{CaO}$ $\mathrm{SiO}_{2}-\mathrm{Al}_{2} \mathrm{O}_{3}$ system. Our results show that the carbide capacity of the high-basicity slag is more than twice that of the simulated BF slag.

\subsection{Iron Carburization through Slags}

In this work, the carburization rate of an iron sheet through a slag phase is investigated. It is therefore necessary to take into account the transport phenomena of carbon through the slag phase by combining the transport of carbon to the slag and that from the slag to the metal. In the first stage, i.e., carbon transport to the slag, the rate increases with increasing slag basicity and decreasing oxygen partial pressure. In contrast, in the second stage, i.e., carbon transport from the slag to the metal, the rate increases with decreasing slag basicity and increasing oxygen partial pressure; i.e., the advantageous conditions for carburization are opposite in the two continuous stages. For this reason, it is considered that the overall reaction of iron carburization 
through slag is generally difficult to accomplish. We now examine the advantageous conditions for achieving carburization by considering the overall reaction rate.

The profile of the carbon contents of the carburization reaction through the successive phases of carbon, slag, and iron are shown in Fig. 4. The carburization reaction is composed of transport of carbon to the slag, transport of carbon from the slag to iron, and the reactions at the carbon/slag and slag/metal interfaces. The equation for the overall carburization reaction, including all of these transport and reaction steps, is derived as follows. Although the dissolution of carbon in the slag is generally expressed by Eq. (2), for convenience, we now define it by Eq. (7). The carbide capacity for Eq. (7) is then expressed by Eq. (8):

$$
\begin{array}{r}
\mathrm{C}(\mathrm{s})+\frac{1}{2} \mathrm{O}^{2-} \text { (in slag) }=\mathrm{C}^{-}(\text {in slag })+\frac{1}{4} \mathrm{O}_{2}(\mathrm{~g}) \ldots \ldots . .(7) \\
C_{\mathrm{C}^{-}}=\frac{N_{\mathrm{C}^{-}} \cdot P_{\mathrm{O}_{2}}^{\frac{1}{4}}}{a_{\mathrm{C}}} \ldots \ldots \ldots \ldots \ldots \ldots \ldots \ldots \ldots \ldots \ldots \ldots \ldots \ldots \ldots
\end{array}
$$

where $N_{\mathrm{C}^{-}}$denotes the molar ratio of $\mathrm{C}^{-}$in slag. The reactions at (a) the carbon/slag and (b) the slag/metal interfaces are assumed to be sufficiently fast and at virtual equilibrium; the following equations then hold:

$$
\begin{gathered}
\text { (a): } K_{(7)}=\frac{a_{\mathrm{C}^{-}} \cdot P_{\mathrm{O}_{2}}^{\frac{1}{4}}}{a_{\mathrm{C}} \cdot a_{\mathrm{O}^{2-}}^{\frac{1}{2}}}=\frac{\left(\gamma_{\mathrm{C}^{-}} \cdot N_{\mathrm{C}^{-}}^{(\mathrm{a})}\right) \cdot P_{\mathrm{O}_{2}}^{\frac{1}{4}}}{a_{\mathrm{O}^{2-}}^{\frac{1}{2}}} \cdots \cdot . \\
\text { (b) }: K_{(7)}=\frac{a_{\mathrm{C}^{-}} \cdot P_{\mathrm{O}_{2}}^{\frac{1}{4}}}{a_{\mathrm{C}} \cdot a_{\mathrm{O}^{2-}}^{\frac{1}{2}}}=\frac{\left(\gamma_{\mathrm{C}^{-}} \cdot N_{\mathrm{C}^{-}}^{(\mathrm{b})}\right) \cdot P_{\mathrm{O}_{2}}^{\frac{1}{4}}}{\left(\gamma_{\mathrm{C}} \cdot N_{\mathrm{C}}^{(\mathrm{b})}\right) \cdot a_{\mathrm{O}^{2-}}^{\frac{1}{2}}} \cdots
\end{gathered}
$$

where $K_{(7)}$ and $N_{\mathrm{k}}^{(i)}$ denote the equilibrium constant for Eq. (7) and the molar ratio of component $k$ at the interface, $(i)$, respectively. The mass-transfer rate-equations at the carbon/ slag, slag/metal (slag side), and slag/metal (metal side) interfaces, respectively, are expressed as follows:

$$
\begin{aligned}
& n=k_{\mathrm{S}}\left(N_{\mathrm{C}^{-}}^{(\mathrm{a})}-N_{\mathrm{C}^{-}}\right) \\
& n=k_{\mathrm{S}}\left(N_{\mathrm{C}^{-}}-N_{\mathrm{C}^{-}}^{(\mathrm{b})}\right) \\
& n=k_{\mathrm{M}}\left(N_{\mathrm{C}}^{(\mathrm{b})}-N_{\mathrm{C}}\right)
\end{aligned}
$$

where $k_{\mathrm{S}}\left[\mathrm{mol} /\left(\mathrm{m}^{2} \mathrm{~s}\right)\right]$ and $k_{\mathrm{M}}\left[\mathrm{mol} /\left(\mathrm{m}^{2} \mathrm{~s}\right)\right]$ are the mass-

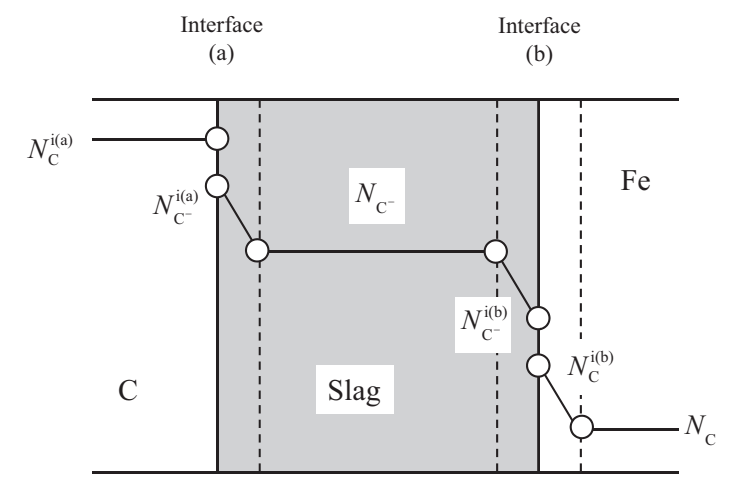

Fig. 4. Profile of carbon contents through successive phases of carbon, slag, and iron. transfer coefficients of carbon in the slag and in the metal, respectively. By solving Eqs. (8) through (13) simultaneously, the overall rate-equation of the carburization reaction at the steady-state is as follows:

$$
\frac{n}{k}=1-\gamma_{\mathrm{C}} N_{\mathrm{C}}\left(\frac{1}{k}=\frac{2 P_{\mathrm{O}_{2}}^{1 / 4}}{k_{\mathrm{S}} C_{\mathrm{C}^{-}}}+\frac{\gamma_{\mathrm{C}}}{k_{\mathrm{M}}}\right)
$$

where $k$ is the apparent overall rate constant of the carburization reaction, $N_{\mathrm{C}}$ the molar ratio of $\mathrm{C}$ in metal and $\gamma_{\mathrm{C}}$ the activity coefficient of carbon in metal, and the reciprocal of the rate constant, $1 / k$, represents the resistance of the overall carburization reaction. Using the reaction area of the slag/ metal interface, $A\left[\mathrm{~m}^{2}\right]$, and the number of moles of carbon in the iron, $n_{\mathrm{C}}[\mathrm{mol}]$, the mass-transfer flux, $n\left[\mathrm{~mol} /\left(\mathrm{m}^{2} \mathrm{~s}\right)\right]$, can be expressed as follows:

$$
n=\frac{1}{A} \frac{d n_{\mathrm{C}}}{d t}
$$

From Eqs. (14) and (15), the variation in the carbon content of the iron with time is expressed by

$$
\frac{d n_{\mathrm{C}}}{d t}=A k\left(1-\gamma_{\mathrm{C}} N_{\mathrm{C}}\right)
$$

Integration of Eq. (16) from 0 to time $t$ [s] gives

$$
\frac{n_{\mathrm{C}, t}-n_{\mathrm{C}, 0}}{A\left(1-\gamma_{\mathrm{C}} N_{\mathrm{C}}\right)}=k t
$$

where $n_{\mathrm{C}, t}[\mathrm{~mol}]$ denotes the content of carbon in the iron at $t$ [s] and $n_{\mathrm{C}, 0}[\mathrm{~mol}]$ the content of carbon in the iron at $0 \mathrm{~s}$ $\left(n_{\mathrm{C}, 0}=2.79 \times 10^{4} \mathrm{~mol}\right.$ in this work $)$. If the surface area of the iron sheet is assumed to be constant during the experiments, the reaction area can be estimated to be $A=4.20 \times$ $10^{-4} \mathrm{~m}^{2}$. The left-hand side of Eq. (17) can be calculated by substituting the values for $n_{\mathrm{C}, t}$ and $N_{\mathrm{C}}$ from the experimental results into Eq. (17) for each time. In Fig. 5, the left-hand side of Eq. (17) is plotted against $t$ [s]. In the initial stage of the carburization reaction, the left-hand side of Eq. (17) is negative for both slags, which means that the carbon content of the iron has decreased from the initial level. This is because the initial carbon content of the iron is higher than that of the slag, and carbon is transported from the metal to the slag in the initial stage of the reaction. Except for the

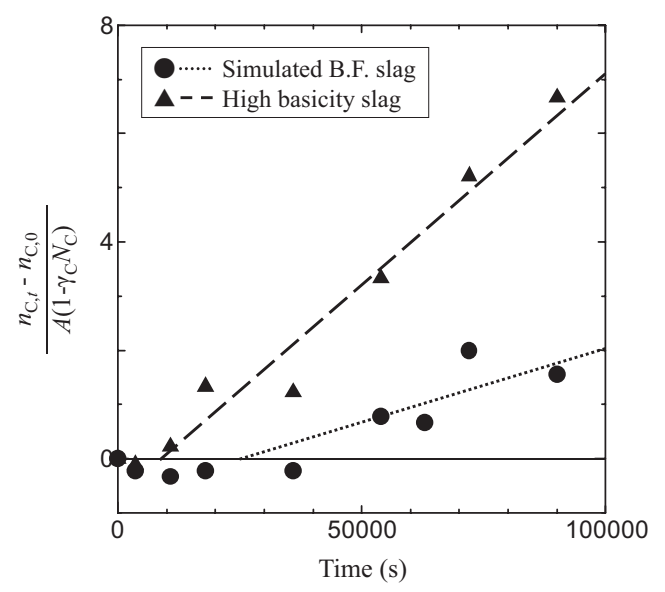

Fig. 5. Variations in the value of the left-hand side of Eq. (17) with time. 
results in the initial stage, the linear regression line is described in Fig. 5 by the least-squares method. From the slope of the straight line in Fig. 5, the apparent rate constant of the carburization reaction is derived to be $k=2.71 \times 10^{-5}$ $\mathrm{mol} /\left(\mathrm{m}^{2} \mathrm{~s}\right)$ for the simulated BF slag, and $k=8.00 \times 10^{-5}$ $\mathrm{mol} /\left(\mathrm{m}^{2} \mathrm{~s}\right)$ for the high-basicity slag. It is found that the rate constant for the high-basicity slag is larger than that for the simulated BF slag. From Eq. (14), it is expected that the rate constant will increase with increasing carbide capacity of the slag. The present results are in accord with the fact that the carbide capacity increases with slag basicity, as described in Section 4.1.

Figure 2 shows that the carbon content of the iron does not increase for a period after the start of the experiment. This is because, in the initial stage of the reaction, the initial carbon activity of the slag is lower than that of the metal, and carbon is transported to the slag from both sides of the carbon and metal phases, before carburization of the metal by the carbon in the slag phase begins. Accordingly, the intersection point of the regression lines and the horizontal axis (the left-hand side of Eq. $(17)=0$ ) in Fig. 5 can be considered to be the time at which carburization of the metal through the slag starts. The time, derived from the coordinate of the intersection point of the regression lines and the horizontal axis in Fig. 5, is $23700 \mathrm{~s}(\sim 6.6 \mathrm{~h})$ for the simulated BF slag, and $9370 \mathrm{~s}(\sim 2.6 \mathrm{~h})$ for the high-basicity slag. These results also show that the carburization rate for the high-basicity slag, which has a higher carbide capacity, is faster than the rate for the simulated BF slag.

When we consider the fact that the mass-transfer rate of carbon in metal is much faster than that in slag, i.e., $k_{\mathrm{M}} \gg k_{\mathrm{S}}$, the following equation holds instead of the equation in parentheses in Eq. (14).

$$
\frac{1}{k} \approx \frac{2 P_{\mathrm{O}_{2}}^{1 / 4}}{k_{\mathrm{S}} \mathrm{C}_{\mathrm{C}^{-}}}
$$

By substituting the known values in Eq. (8), the values for $C_{\mathrm{C}^{-}}$are calculated to be $1.82 \times 10^{-9}$ for the simulated $\mathrm{BF}$ slag and $4.30 \times 10^{-9}$ for the high-basicity slag. By substituting these $C_{\mathrm{C}^{-}}$values, the values for the apparent rate constant of the carburization reaction, and the oxygen partial pressure in Eq. (18), the mass-transfer coefficient for carbon in the slag is calculated to be $k_{\mathrm{S}}=0.29 \mathrm{~mol} /\left(\mathrm{m}^{2} \mathrm{~s}\right)$ for the simulated BF slag, and $k_{\mathrm{S}}=0.37 \mathrm{~mol} /\left(\mathrm{m}^{2} \mathrm{~s}\right)$ for the highbasicity slag. Using these derived values for the masstransfer coefficient of carbon in the slag, the carbon content of the slag after $20 \mathrm{~h}$ is calculated to be 0.0013 mass $\%$ for the simulated BF slag, and 0.0036 mass $\%$ for the highbasicity slag. These carbon contents of the slags at the steady-state are lower than the equilibrium values. Using the density of the slag, which is estimated to be $2.7 \times 10^{3} \mathrm{~kg} / \mathrm{m}^{3}$ for both slags in this work, ${ }^{16,17)}$ and the mean molecular masses, which are $6.35 \times 10^{-2}$ for the simulated BF slag, and $7.01 \times 10^{-2} \mathrm{~kg} / \mathrm{mol}$ for the high-basicity slag, the units of the mass-transfer coefficient can be converted. The derived values are $k_{\mathrm{S}}=7.0 \times 10^{-6} \mathrm{~m} / \mathrm{s}$ for the simulated BF slag, and $k_{\mathrm{S}}=9.5 \times 10^{-6} \mathrm{~m} / \mathrm{s}$ for the high-basicity slag. This shows that the mass-transfer coefficient of carbon in the high-basicity slag, which has a higher carbide capacity, is larger than that in the simulated BF slag. From these results, we can conclude that the rate of carburization through the successive phases of carbon, slag, and metal is faster in the case of the slag with higher basicity.

\section{Conclusions}

The carbide capacity of $\mathrm{CaO}-\mathrm{SiO}_{2}-\mathrm{Al}_{2} \mathrm{O}_{3}$ slags and the iron carburization rates through successive phases of carbon, slag, and metal are measured at $1723 \mathrm{~K}$. The conclusions are as follows.

(1) The carbide capacity of the high-basicity slag is higher than that of the simulated BF slag.

(2) The rate of iron carburization through $\mathrm{CaO}-\mathrm{SiO}_{2}-$ $\mathrm{Al}_{2} \mathrm{O}_{3}$ slag is much smaller than that of direct carburization or that through a slag including iron oxide.

(3) The rate of iron carburization through a slag of higher basicity is faster. The rate increases with increasing slag basicity, increasing carbide capacity, and decreasing oxygen partial pressure.

\section{REFERENCES}

1) Ministry of Economy, Trade and Industry Government of Japan: 2009 Annual Report on Energy (Japan's "Energy White Paper 2010"), Energy-forum, Tokyo, (2009).

2) H. Tanaka: Bull. Iron Steel Inst. Jpn., 14 (2009), 766.

3) A. Kasai, M. Naitou, Y. Matsui and J. Yamagata: Tetsu-to-Hagané, 89 (2003), 1212.

4) T. Harada, O. Tsuge, H. Tanaka, I. Kobayashi and H. Uemura: Kobe Steel Eng. Rep., 55 (2005), 128.

5) M. Inoue, H. Watanabe, H. Sakakiyama, K. Takatani and Y. Oda: Tetsu-to-Hagané, 72 (1986), S885.

6) S. Takagi, H. Maeda, A. Yumura, K. Takatani, T. Osawa, Y. Fujiwara and K. Mio: Tetsu-to-Hagané, 72 (1986), S886.

7) A. Kasai, Y. Matsui, F. Noma, H. Iwakiri and M. Shimizu: Tetsu-toHagané, 87 (2001), 313.

8) N. Ishiwata, Y. Sawa and K. Takeda: CAMP-ISIJ, 15 (2002), 100.

9) ISIJ: Iron and Steel Production Method (Ironmaking - Steelmaking), Maruzen, Tokyo, (1972), 103, 111.

10) K. Nagata: CAMP-ISIJ, 18 (2005), 30.

11) Y. Iguchi and S. Endo: CAMP-ISIJ, 17 (2004), 148.

12) T. Ikeda and M. Maeda; Tetsu-to-Hagané, 77 (1991), 23.

13) J. H. Park and D. J. Min: ISIJ Int., 44 (2004), 223.

14) The 19th Committee on Steelmaking: Chemical Properties of Molten Slags, The Japan Soc. for the Promotion of the Science, ISIJ, Tokyo, (1991), 187, 189, 196.

15) S. Ban-ya: Ferrous Process metallurgy, The Japan Institute of Metals, Sendai, (2000), 34

16) A. Nishiwaki and K. Ogiwara: Tetsu-to-Hagané, 71 (1985), S121.

17) T. Koshida, T. Ogasawara and H. Kishidaka: Tetsu-to-Hagané, 67 (1981), 1491. 